\title{
DA SUBJETIVIDADE MELANCÓLICA: UMA LEITURA DE “ANOITECER”, DE FLORBELA ESPANCA
}

\section{ON MELANCHOLIC SUBJECTIVITY: A READING OF “ANOITECER”, BY FLORBELA ESPANCA}

\author{
Henrique Marques Samyn* \\ UERJ
}

Resumo: Temas associados à melancolia aparecem frequentemente na poesia de Florbela Espanca, mas esse motivo raramente é analisado mais minuciosamente. Este artigo tenciona apresentar uma leitura para “Anoitecer", poema publicado no Livro de "Soror Saudade" (1923), enfatizando o modo como o cenário crepuscular e o tema da melancolia se articulam com uma subjetividade figurada como transcendente e indescritível.

Palavras-chave: Melancolia. Subjetividade. Florbela Espanca. Autoria feminina. Literatura portuguesa.

\begin{abstract}
Melancholy-related themes appear frequently in Florbela Espanca's poetry, but rarely are analysed in detail. This paper aims to present a reading of "Anoitecer", a poem published in Livro de "Soror Saudade" (1923), emphasizing the relation of the evening scenery and the melancholy motif with a subjectivity figured as transcendent and indescribable.
\end{abstract}

Keywords: Melancholy. Subjectivity. Florbela Espanca. Female Authorship. Portuguese Literature.

\section{“Anoitecer”}

"Talvez seja eu, com o meu tristíssimo poder de entristecer todos os que me estimam, todos os que comigo vivem, talvez seja eu que a entristeça às vezes” - escreve Florbela Espanca (1986, p. 135-136) em carta enviada à sua amiga Júlia Alves, datada de 8 de julho de 1916, antes de manifestar o desejo de encontrá-la pessoalmente; ideia que não se concretizaria até a morte da poetisa, quase uma década e meia depois. A insistência de Florbela em sua própria infelicidade aparece recorrentemente nas primeiras cartas enviadas à Júlia, que conhecera ainda em 1916, e que se tornaria sua maior confidente; é como se a - então ainda não publicada escritora desejasse insistentemente enfatizar um aspecto de si considerado marcante por ela mesma. Já no início da correspondência enviada à amiga, a poetisa se descrevia como "triste, imensamente triste, duma tristeza amarga e doentia” (1986, p. 123); uns poucos meses depois, ressaltava: "Eu não sou feliz mas nem ao menos te sei dizer porquê” (1986, p. 166).

Não são essas as únicas passagens da correspondência florbeliana que remetem a um estado subjetivo no qual percebemos traços daquilo que, historicamente, passou-se a associar à

* Doutor em Letras pela Universidade do Estado do Rio de Janeiro, é Professor Adjunto e pesquisador procientista do Instituto de Letras da mesma Universidade. 
melancolia, em que pese toda a diversidade de acepções que esse conceito recebeu ao longo do tempo ${ }^{1}$. Para além dos múltiplos (e baldados) esforços de “diagnosticar” os supostos problemas psicológicos, ou mesmo psiquiátricos, de Florbela, fato é que referências à tristeza são frequentes em sua correspondência - e são igualmente comuns em sua produção literária. Anuncia-o o título da primeira obra por ela publicada: o Livro de Mágoas, que já no poema de abertura ressalta ser “só de mágoas cheio” (ESPANCA, 2012a [1919], p. 83). Não obstante, já nesse primeiro livro o tratamento dispensado pela poetisa ao temário associado à melancolia demonstra uma notável complexidade, desfavorecendo análises que o abordem de modo monolítico; por esse motivo, resisto aqui à tentação de apresentar uma síntese, em vez disso limitando-me a destacar dois poemas que abordam esse mesmo motivo de maneira bastante diversa: “Eu”, em que a tristeza emerge associada ao esvaziamento da subjetividade e a um questionamento de cariz identitário; e "Neurastenia”, que tem por motivo a contingência da melancolia e a necessidade de encontrar meios para expressá-la.

É em respeito à densidade da poética florbeliana que apresento, neste artigo, uma análise de um único soneto, constante do segundo livro assinado pela autora; refiro-me a "Anoitecer”, estampado no Livro de "Soror Saudade", publicado em 1923. Nesse poema, o tema da melancolia surge vinculado a um outro motivo recorrente na poética florbeliana: o crepúsculo, também figurado em poesias presentes em todas as obras da autora, igualmente de modo plurívoco ${ }^{2}$. Por conta dessa "complexidade inerente” (SAMYN, 2016, p. 34) à obra de Florbela, proponho-me aqui a apresentar uma leitura em profundidade de “Anoitecer”, numa tentativa de explorar de que modo a figuração do momento crepuscular e o tratamento da melancolia se articulam, nessa composição, de modo singular e específico.

Começo transcrevendo o soneto (ESPANCA 2012b [1923], p. 117):

A luz desmaia num fulgor d'aurora,

Diz-nos adeus religiosamente...

E eu que não creio em nada, sou mais crente

Do que em menina, um dia, o fui... outrora...

Não sei o que em mim ri, o que em mim chora,

Tenho bênçãos d'amor p'ra toda a gente!

E a minha alma sombria e penitente

Soluça no infinito desta hora...

Horas tristes que são o meu rosário...

Ó minha cruz de tão pesado lenho!

Ó meu áspero e intérmino Calvário!

\footnotetext{
${ }^{1}$ Cf. infra, nota 13.

${ }^{2}$ Apenas em O Livro de "Soror Saudade”, referências ou alusões à noite e ao crepúsculo ocorrem em: “Fumo”, “A noite desce...”, "Prince Charmant...”, "Esfinge”, “Tarde demais...”, “Noturno”, “Crepúsculo”, "Renúncia”, "Horas rubras”, "Princesa desalento” e "Sombra".
} 
E a esta hora tudo em mim revive:

Saudades de saudades que não tenho...

Sonhos que são os sonhos dos que eu tive...

(ESPANCA 2012b [1923], p. 117)

\section{Subjetividade e contradição}

Conjugam-se imagens contraditórias no verso que abre o soneto: o crepuscular cenário, descrito de forma a evocar o enlanguescimento, resulta num resplendor semelhante ao da aurora - remetendo, portanto, a um período do dia que lhe é oposto. À primeira vista, essa contradição parece meramente instaurar um estranhamento, sugerindo não ser este um anoitecer ordinário; algo compreensível, por exemplo, enquanto percepção subjetiva de um fenômeno natural. Não obstante, parece-me que a ideia de um crepúsculo que em si encerra o seu avesso aqui ocorre por uma razão deliberada, uma vez que antecipa uma complexa noção que serve como clave de leitura para todo o soneto - e que tem um precedente na filosofia quatrocentista.

É no século XV, com o filósofo germânico Nicolau de Cusa (1401-1464), que o conceito de coincidentia oppositorum alcança sua formulação mais conhecida, enquanto unidade ou verdade transcendente na qual a multiplicidade da finitude encontra resolução e inteligibilidade. Ainda que todas as coisas estejam ontologicamente presentes em Deus antes de serem criadas, isso não implica uma identificação imediata entre Deus e a multiplicidade fenomênica, o que implicaria uma concepção panteísta. Em decorrência disso, Deus é concebido como superior à racionalidade humana - sendo, portanto, impossível conhecê-lo: enquanto indiferenciado, ele está para além de quaisquer determinações. Qualquer discurso sobre Deus será, por conseguinte, inevitavelmente metafórico ${ }^{3}$.

Aqui, não proporei uma interpretação do soneto de Florbela a partir do conceito proposto por Cusanus, o que implicaria num evidente (e inaceitável) anacronismo; tampouco pretendo sugerir que a poetisa portuguesa tenha deliberadamente resgatado um conceito filosófico-teológico cunhado no século XV (sobretudo porque desconheço quaisquer indícios de que Florbela tenha, em algum momento, estabelecido contato com sua obra). Minha argumentação seguirá em outro sentido: entendo que, em “Anoitecer”, Florbela Espanca constrói um discurso de contradições e paradoxos que remete a uma concepção particular de subjetividade, enquanto fundamento transcendente descritível apenas de modo metafórico; está aí a aproximação, por via estritamente analógica, com a noção de coincidentia oppositorum.

Dito isso, retorno ao primeiro verso do soneto. Ao descrever o crepúsculo como um lânguido momento que resulta num brilho semelhante ao da aurora, o discurso poético remete a uma percepção subjetiva que reconhece (de forma contingente, mas não absurda) uma similaridade entre dois distintos fenômenos naturais; e, se essa aproximação poderia parecer despropositada à sensibilidade de quem lê o poema, Florbela logo trata de apaziguar essa tensão por intermédio de um recurso retórico - ao incluir, no segundo verso, uma construção pronominal

\footnotetext{
${ }^{3}$ Porque aqui evoco apenas instrumentalmente os conceitos de Cusanus, limito-me a expor alguns poucos elementos fundamentais. Para sínteses mais desenvolvidas de De docta ignorantia, do conceito de coincidentia oppositorum e de sua repercussão no âmbito medieval, cf. Watts (1982), especialmente o capítulo II; Helander, B. H. (1996); Moran (2007).
} 
que inclui a instância receptora. Desse modo, aquela singular percepção é tratada como comum à subjetividade lírica e à subjetividade leitora; e de ambas o crepúsculo, já agora personificado, despede-se “religiosamente”, o que acaba por inspirar (agora, apenas no sujeito poético) uma propensão para a crença que a faz recordar a própria infância.

Parece-me relevante que a religiosidade derive da própria natureza personificada, como se não fosse nela projetada pelo sujeito poético - ou como se o crepúsculo instigasse a subjetividade a dispor-se diante dele de um modo especificamente religioso. Mas em que sentido devemos compreender, aqui, essa emanação de uma religiosidade desde a natureza? Sabemos que, historicamente, a procura pela raiz etimológica de 'religio' ensejou duas possibilidades4: a do gramático romano Sérvio, também mencionada por Cícero e Agostinho, que remete a 'religare'; e a proposta pelo mesmo Cícero, que remete a 'relegere' - o que forneceria dois sentidos fundamentais: de um lado, a recuperação de um vínculo; de outro, uma nova leitura, ou uma nova interpretação, de algo. Por conseguinte, os dois primeiros versos da composição de Florbela podem ser lidos como um convite, ensejado pelo paradoxal aspecto do fenômeno crepuscular, que enseja algum tipo de "religação" ou "releitura” nas subjetividades poética e leitora; em outras palavras: um acontecimento ordinário, ao ser percebido de uma maneira distinta, acaba por ensejar uma desestabilização na ordem subjetiva.

Isso já acarreta um efeito imediato, descrito no restante dessa primeira estância: falando de si mesmo, o sujeito lírico abandona o ceticismo e torna-se "mais crente" do que foi outrora, na infância. Conquanto seja legítimo reconhecer aqui um sentido (auto)biográfico, mormente pela identificação entre os gêneros da autora empírica (Florbela Espanca) e da subjetividade figurada (que se descreve como “menina”), parece-me mais instigante atentar para a referência a um sujeito lírico que resgata em si um estado aparentemente perdido, na medida em que assim se constitui um processo análogo ao descrito nos versos iniciais: assim como o crepúsculo resgata em si a aurora, a subjetividade adulta resgata em si a infante - o que alude para o fato de que, em ambos os casos, há instâncias mais profundas (indiferenciadas), parcialmente manifestas em estados parcelares (opostos): anoitecer/aurora, maturidade/infância. Note-se ainda que a menção ao "nós", no segundo verso, sugere que o mesmo tipo de experiência pode ter lugar na subjetividade leitora.

\section{Vazio e transcendência}

O segundo quarteto se abre com mais uma contradição, dando prosseguimento ao discurso literário presente na estância inicial. Ao expressar uma incerteza sobre sua própria condição, que se manifesta de forma paradoxal - ora rindo, ora chorando -, o sujeito lírico alude a uma espécie de essência indescritível: um “não sei o que” que ultrapassa a linguagem, uma vez que toda tentativa de definição incorre em aspectos contraditórios. O notável domínio de recursos retóricos por Florbela Espanca pode ser percebido no modo como, logo após sugerir a indescritibilidade dessa essência de si, evoca definidores cuja provisoriedade se evidencia pela vagueza e pela imprecisão. Vejamos de que modo isso ocorre.

Primeiro, temos a ideia de uma subjetividade disposta a espalhar, “p'ra toda a gente”, "bênçãos d'amor”. Essa imagem se vincula ao resgate da crença mencionado no fim da estrofe

\footnotetext{
${ }^{4}$ Remeto ao artigo clássico de Hoyt (1912).
} 
anterior: é a recuperação da religiosidade, supostamente perdida, o que faculta essa distribuição de favores. Mas como isso pode ser possível, quando essa disposição se fundamenta num resgate, súbito e inesperado, de uma condição religiosa motivada por um fenômeno exterior e contraditório? Ou mais: como isso pode ser possível, quando a própria subjetividade se revela instável e inconsistente, a tal ponto que nem mesmo dispõe dos recursos necessários para conhecer a si mesma? Em que pese essa precariedade existencial, o que temos é uma subjetividade que se dispõe a agir em função de um afeto (que sequer é capaz de reconhecer em si) a "toda a gente” (sintagma cuja imprecisão opera como denúncia de contingência).

Em segundo lugar, o que temos nos dois últimos versos dessa segunda estrofe é uma tentativa de definição da essência subjetiva cuja arbitrariedade se torna patente pelo modo repentino como ocorre - como é possível que, logo após ressaltar o desconhecimento de si, já seja o sujeito lírico capaz de definir-se? Para além disso, a sugestão de uma abnegação extrema, delineada por um acúmulo de elementos que enfatizam sua condição de mártir (a alma penitente que, a despeito de sua precariedade, põe-se a espalhar indiscriminadamente bênçãos de um amor que nem mesmo tem a certeza de possuir), salienta uma propensão à renúncia que radicaliza ad absurdum o discurso literário: como uma subjetividade incapaz de conhecer-se e definir-se pode, finalmente, abdicar de si?

O verso final do segundo quarteto dilata infinitamente esse processo de renúncia, o que intensifica e reitera o que, já no momento em que fora proposto, parecia absurdo. Se levamos até as últimas consequências o que está sendo dito, de fato, talvez possamos concluir que o discurso florbeliano remete a uma performance que prescinde de um sujeito; trata-se de um gesto que sustenta a si mesmo - redutível, nos limites do verso final, a um ato de soluçar (já que proveniente de uma "alma” esvaziada) que se prolonga infinitamente. O que resulta, portanto, de todo esse processo é uma subjetividade oca, manifesta em atos que se inscrevem em uma espécie de vacuidade. Mas, se nada há subjacente ao gesto, o que propriamente o determina? Como pode haver um soluçar sem haver alguém que soluça? Para além disso: quem é esse sujeito que fala de si, que descreve seus atos e seus gestos, e que chega a ponto de qualificar sua própria alma, logo após haver reconhecido a impossibilidade de fazê-lo?

O que resulta desse conjunto de paradoxos, e que doravante passará a predominar na composição, é a tácita certeza da impossibilidade de se oferecer uma descrição delimitada e peremptória da subjetividade - pressuposto que está insinuado desde os primeiros versos da composição, mas que é (algo sub-repticiamente) reiterado pelo discurso lírico ao longo do soneto. Os tercetos finais, como logo observaremos, constituem a culminância desse processo.

\section{A premência da metáfora}

$\mathrm{O}$ primeiro terceto se abre com um verso que resgata aquele que encerrara o segundo quarteto. A hora que se estendia ao infinito, na qual se efetivava o gesto de soluçar, agora é multiplicada em "horas tristes" comparadas a um rosário - imagem sobre a qual vale refletir com algum vagar. A tradição católica atribui a origem do rosário a são Domingos de Gusmão, que teria recebido de Maria a inspiração para rezar o rosário como um antídoto contra o pecado e a heresia, em resistência à heresia albigense; ora a Alano de la Roche, dominicano do século XV que, por sua vez, atribuiria a invenção a são Domingos (cf. THURSTON; SHIPMAN, 1912). 
Para além das controvérsias em torno de sua origem, ao longo do tempo essa rotina devocional mariana, que associa a recitação de orações à contemplação de passagens da vida de Jesus e Maria, consolidou-se como uma das principais práticas de oração católicas. No âmbito do discurso lírico elaborado por Florbela, a comparação das "horas tristes” com o rosário parece remeter à ideia de um longo ritual, realizado segundo uma rotina previamente estabelecida; desse modo, os momentos de pesar se sucedem de modo regular e ordenado, exigindo do sujeito poético uma dedicação comparável àquela exigida pelo ritual religioso.

Esse verso que abre os tercetos tem, assim, um par de desdobramentos. De um lado, sugere a imersão em um ato contemplativo - cujo objeto, entretanto, não são os mistérios religiosos, mas sim a própria tristeza. Não obstante, a contemplação da tristeza não permite percebê-la imediatamente como decorrente de uma subjetividade (como, no verso final do segundo quarteto, o ato de soluçar), uma vez que essa foi previamente esvaziada; o que resta é a possibilidade de considerá-la efeito de uma subjetividade que não se oferece à contemplação imediata. Por outro lado, a evocação de elementos religiosos (já antecipada na segunda estância) abre espaço para as duas imagens presentes nos versos restantes deste primeiro terceto, que constituem um discurso metafórico cuja especificidade deve ser considerada.

A referência, no segundo verso, à “cruz de tão pesado lenho” não apenas dá prosseguimento ao registro de cariz religioso, mas também insere um elemento que instaura uma nova inflexão no discurso poético. Em uma primeira leitura, a cruz pode ser lida como metáfora para o sofrimento que incide sobre a subjetividade lírica; nesse caso, o verso seguinte tem o sentido retórico de sugerir a gravidade dessa dor, sobretudo por conta da evocação explícita do Calvário - de Calvarice Locus, expressão utilizada na Vulgata como referência ao Gólgota, citado em três dos evangelhos canônicos como local onde Jesus foi crucificado (Mc 15, 22; Mt 27, 33; Jo 19, 17). A pertinência dessa leitura, bem como a mestria retórica de Florbela, revela-se quando observamos mais atentamente a construção desses versos: ao situar "minha cruz" na abertura do verso intermediário e ao deslocar “Calvário” para o fim do terceiro verso, a poetisa cria uma estrutura em quiasmo que inscreve a cruz na própria superfície textual; a repetição do vocativo, de modo anafórico, em versos exclamativos acentua o tom de exaspero; a acumulação de adjetivos ('pesado’, ‘áspero', ‘intérmino’) intensifica esse conjunto de referências.

Penso, contudo, que há algo mais a ser observado neste terceto. Se a metafórica evocação da figura de Jesus Cristo não constitui um elemento inédito no discurso poético - em especial o finissecular, que tanto influenciou a construção da poética florbeliana -, o modo como isso é feito neste momento me parece significativo, precisamente na medida em que se ajusta precisamente ao conceito de coincidentia oppositorum que venho adotando como clave para interpretação de “Anoitecer”. A meu ver, a questão crucial é que, após consumado o esvaziamento da subjetividade, a figura crística emerge como referencial metafórico que opera de modo substitutivo; de fato, é ela quem fornece os elementos que permitem um discurso sobre a subjetividade - uma vez que, tendo sido reduzida ao vazio, esta não pode mais ser positivamente qualificada de forma alguma. Consoante essa perspectiva exegética, é nesse momento que o procedimento florbeliano, análogo ao conceito cunhado por Nicolau de Cusa, atinge o ápice, pelo reconhecimento das incontornáveis limitações no que tange ao que pode ser dito sobre a subjetividade (transcendente): a descrição possível não supera, afinal, o discurso metafórico (constante do 
primeiro terceto), uma vez que aquela só pode ser concebida a partir de uma multiplicidade de efeitos contraditórios (presentes no primeiro e no segundo quartetos).

\section{Da subjetividade melancólica}

O terceto final constitui um derradeiro desdobramento do intricado procedimento discursivo construído por Florbela Espanca ao longo do soneto. Em uma nova e final inflexão - que, por outro lado, remeterá ao que já foi dito nos quartetos -, a poetisa voltará a falar da subjetividade, mas agora empregando um discurso que radicalizará o recurso aos paradoxos (notavelmente pelo registro sintético).

O verso inicial indicia um retorno à subjetividade, no âmbito da experiência ritualística constituída a partir dos momentos de tristeza infinitamente dilatados. A revivescência ali mencionada sugere, à primeira leitura, uma nova tentativa de descrição da subjetividade - tarefa que poderia ser realizada à maneira do que foi feito na estância anterior; nesse caso, Florbela poderia recorrer a mais um conjunto de elementos crísticos, ampliando o referencial metafórico e, eventualmente, reiterando as limitações impostas a qualquer tentativa de descrição da subjetividade. Em vez disso, o que faz Florbela é recuperar uma discursividade ancorada em paradoxos, desse modo enfatizando o vazio da subjetividade - e, concomitantemente, afirmando a sua transcendência. A esse respeito, é relevante que o eu lírico se refira a um "tudo" que renasce em si, como se estivesse aludindo ao que lhe é mais essencial.

No penúltimo verso do soneto, o sujeito lírico menciona as "[s]audades das saudades que não tenho...”; portanto, a um afeto evocatório que remete a outra sorte de sentimentos que, entretanto, não lhe dizem respeito. Tratando-se a saudade de um afeto que se efetiva a partir de uma ausência ou perda, como compreender que essa falta possa estar associada a uma outra falta de algo que, no entanto, sequer existe? O que o verso enfatiza, com efeito, é a dimensão lacunar dessa associação de afetos: não se trata, afinal, de sentir saudades de algo que não se tem, mas sim de sentir saudades de outras saudades que inexistem. Todavia, se tudo aqui remete à ausência, o fato é que nem por isso o afeto deixa de existir - e, mais do que isso, de operar como um possível e provisório definidor para aquela subjetividade que não pode ser descrita.

Já no verso final, a subjetividade poética alude a "sonhos que são os sonhos dos que eu tive”. Embora a positividade da construção discursiva possa sugerir uma inversão do que foi dito no verso anterior, o que aqui temos é uma referência a vivências oníricas que são outros sonhos outrora existentes; em outras palavras: sonha-se com algo que já foi sonhado em um momento passado - mas que, na medida em que retorna (no presente) como sonho, não logrou ultrapassar as fronteiras do próprio espaço onírico. Não se concretiza, por conseguinte, a expectativa de que o discurso assuma uma direção positiva; mais uma vez, há meramente a afirmação da falta.

É precisamente isso o que permite caracterizar, a meu ver, a subjetividade figurada (embora não definida) no soneto de Florbela como essencialmente melancólica, na medida em que se pode pensar a melancolia como um vazio estrutural, um desequilíbrio na constituição individual ou um anseio por um objeto perdido ${ }^{5}$. O que é isso que falta, que é alvo de saudades que se dobram, de sonhos que retornam como novas experiências oníricas, num processo que - ao

\footnotetext{
${ }^{5}$ Aludo aqui a várias definições possíveis a fim de não me restringir à definição psicanalítica. Sobre as variações históricas do conceito, cf. Berlinck (2008) e Földényi (2016).
} 
menos psicologicamente - estende-se ad infinitum? O notável é que, se em nenhum momento isso é nomeado, por outro lado está de algum modo vinculado ao que o sujeito concebe como sua própria essência, ainda que não seja possível afirmá-lo de modo categórico (na medida em que essa essência foge a qualquer tentativa de definição).

Penso ainda que é fundamental, neste momento, recuperar a emanação de religiosidade desde a natureza que surge na primeira estância, à maneira de prenúncio para o conjunto de outras referências religiosas que emerge ao longo da composição. Como já tive oportunidade de observar, as duas hipóteses etimológicas em torno de 'religio' remetem ou à ideia de recuperação de um elo ('religare') ou a uma nova leitura ou interpretação ('relegere'). Pois bem: a meu ver, o “anoitecer” figurado na composição constitui, efetivamente, um fenômeno ensejador de uma experiência cuja religiosidade remete não a uma divindade, mas à subjetividade, que encontra assim ocasião tanto para reestabelecer um vínculo consigo mesma quanto para reinterpretar-se. O que singulariza essa experiência é a percepção da transcendência da subjetividade, que só se torna descritível parcialmente e de modo metafórico - o que enseja o discurso de paradoxos construído por Florbela Espanca.

Quando, nos versos finais do soneto, o discurso lírico ensaia uma última tentativa de dizer algo acerca da essência da subjetividade, limita-se a caracterizá-la como o lugar de uma ausência. O que se oculta sob a multiplicidade de efeitos, sob o véu das metáforas contraditórias, é isto: um vazio melancólico; uma lacuna ontológica fadada à precariedade - cujo maior sofrimento decorre, porventura, da intolerável consciência de sua própria falta.

\section{Referências}

BERLINCK, L. C. Melancolia: rastros de dor e perda. São Paulo: Humanitas, 2008.

ESPANCA, F. Cartas (1906-1922). Recolha, leitura e notas por R. Guedes. Lisboa: Dom Quixote, 1986.

. Livro de Mágoas. Alonso, C. P.; Silva, F. M. (Org.). Lisboa: Estampa, 2012a [1919].

. Livro de “Soror Saudade”. Alonso, C. P.; Silva, F. M. (Org.). Lisboa: Estampa. 2012b [1923].

FÖLDÉNYI, L. Melancholy. Tradução de Tim Wilkinson. New Haven: Yale University Press, 2016.

HELANDER, B. H. Nicholas of Cusa as theoretician of unity. In: Christianson, G.; Izbicki, T. M. (eds.). Nicholas of Cusa on Christ and the Church. Leiden: E. J. Brill, 1996.

HOYT, S. The Etymology of Religion, Journal of the American Oriental Society, v. 32, n. 2, p. 126-129, 1912.

MORAN, D. Nicholas of Cusa and modern philosophy. In: Hankins, J. The Cambridge companion to Renaissance Philosophy. Nova Iorque: Cambridge University Press, 2007.

SAMYN, H. M. Senhora dos Labirintos, Jornal Rascunho, p. 32-34, maio 2016. 
THURSTON, H., \& SHIPMAN, A. The Rosary. «The Catholic Encyclopedia». Nova Iorque: Robert Appleton Company. Disponível em: http://www.newadvent.org/cathen/13184b.htm. Acesso em: 15 maio 2017.

WATTS, P. M. Nicolaus Cusanus: a fifteenth-century vision of man. Leiden: E. J. Brill, 1982.

Recebido em agosto/2019.

Aceito em dezembro/2019. 